\title{
Registration of W6 26740, W6 26743, and W6 26745 Green Pea Germplasm Resistant to Fusarium Root Rot
}

\author{
Clarice J. Coyne, ${ }^{\star}$ Lyndon D. Porter, Debra A. Inglis, Niklaus J. Grünwald, \\ Kevin E. McPhee, and Fred J. Muehlbauer
}

\begin{abstract}
Three $F_{8}$-derived breeding lines W6 26740 (RIL 846_34; GP-96, PI 652444), W6 26743 (RIL 846_40; GP-97, PI 652445), and W6 26745 (RIL 847_36; GP-98, PI 652446) of green pea (Pisum sativum L.), selected from a recombinant inbred line population developed by the USDA-ARS in 2002, are unique in combining high levels of resistance to Fusarium root rot [caused by Fusarium solani (Mart.) Sacc. f. sp. pisi (F.R. Jones) W.C. Snyder \& H.N. Hans.] with acceptable agronomic traits. They will be useful as a resource for developing root rot resistant green pea cultivars. The parentage of W6 26740, W6 26743, and W6 26745 is a cross between 'Dark Skin Perfection'/90-2131 made in 1994 at Pullman, WA. Dark Skin Perfection is a freezing and canning cultivar characterized by straight, blunt, green, double pods; it was used by pea breeders in the 1950s as a source of resistance to Fusarium wilt race 1 [caused by F. oxysporum Schlecht. f. sp. pisi (van Hall) Snyd. \& Hans]. 90-2131 is a germplasm release characterized by white flowers, green cotyledons, a clear seed coat, a black hilum and dimpled seed. This line has partial resistance to Aphanomyces root rot (caused by Aphanomyces euteiches Drechs.), Fusarium root rot, and Fusarium wilt races 1, 5, and 6. W6 26740, W6 26743 and W6 26746 are expected to serve as parental lines in the development of cultivars with improved disease resistance primarily to Fusarium root rot.
\end{abstract}

$\mathbf{T}^{\mathrm{s}}$ hree $\mathrm{F}_{8}$-derived breeding lines, W6 26740 (RIL 846_34; GP-96, PI 652444), W6 26743 (RIL 846_40; GP-97, PI652445), and W6 26745 (RIL 847_36; GP-98, PI 652446), of green pea (Pisum sativum L.) were selected from a recombinant inbred line population developed by the USDA-ARS in 2000. These lines are unique in combining high levels of resistance to Fusarium root rot [caused

C.J. Coyne, USDA-ARS, Plant Germplasm Introduction and Testing, 59 Johnson Hall, Washington State Univ., Pullman, WA 99164; L.D. Porter, USDA-ARS, Vegetable and Forage Crops Research, 24106 N. Bunn Rd. Prosser, WA 99350; D.A. Inglis, Northwestern Washington Research \& Extension Center, Washington State Univ., Mount Vernon, WA 98273; N.J. Grünwald, USDA-ARS, Horticultural Crops Research Lab., 3420 N.W. Orchard, Corvallis, OR 97330; K.E. McPhee and F.J. Muehlbauer, USDA-ARS, Grain Legume Genetics Physiology Research, 303 E Johnson Hall, Pullman, WA 99164. Registration by CSSA. Received $11 \mathrm{Dec}$. 2007. ${ }^{*}$ Corresponding author (coynec@wsu.edu).

Abbreviations: RFDN, Roza Fusarium Disease Nursery; RIL, recombinant inbred line.

Published in the Journal of Plant Registrations 2:137-139 (2008) doi: 10.3198/jpr2007.12.0674crg

(C) Crop Science Society of America

677 S. Segoe Rd., Madison, WI 53711 USA

All rights reserved. No part of this periodical may be reproduced or transmitted in any form or by any means, electronic or mechanical, including photocopying, recording, or any information storage and retrieval system, without permission in writing from the publisher. Permission for printing and for reprinting the material contained herein has been obtained by the publisher by Fusarium solani (Mart.) Sacc. f. sp. pisi (F.R. Jones) W.C. Snyder \& H.N. Hans.] with acceptable agronomic traits and will be useful as a resource for developing root rot resistant pea cultivars. Fusarium root rot is a serious production constraint in all U.S. pea production areas and five Canadian provinces (Haglund and Kraft, 2001). These lines exceeded the Fusarium root rot resistance of the parental line 90-2131 when screened in the field for four consecutive years (2002-2005) at the Roza Fusarium Disease Nursery (RFDN) located at the Washington State University Irrigated Agriculture Research and Extension Center in Prosser, WA. 'Dark Skin Perfection' was highly susceptible to Fusarium root rot in all $4 \mathrm{yr}$ in the field disease nursery. The expected use of W6 26740, W6 26743, and W6 26745 is as parental lines to develop irrigated green pea cultivars with improved resistance to Fusarium root rot.

\section{Methods Population Development}

The parentage of W6 26740, W6 26743, and W6 26745 is a cross between Dark Skin Perfection/90-2131 (Kraft 1992) made in 1994 at Pullman, WA. Dark Skin Perfection is a freezing and canning cultivar characterized by straight, blunt, and green pods borne doubly on peduncles and was used by pea breeders in the 1950s as a source of resistance to Fusarium wilt race 1 [caused by F. oxysporum Schlecht. f. sp. pisi (van Hall) Snyd. \& Hans]. 90-2131 is a germplasm release characterized by white flowers, green cotyledons, a clear seed coat, a black hilum and dimpled seed (Kraft 
1992) and has partial resistance to Aphanomyces root rot (caused by Aphanomyces euteiches Drechs.), Fusarium root rot, and Fusarium wilt races 1, 5, and 6 (Haglund and Kraft, 2001). The cross, designated X94P275, was made in the field in the summer of 1994. The six $\mathrm{F}_{1}$ seed from one pod were planted in the greenhouse in August 1994, and all $\mathrm{F}_{2}$ seed were planted in November 1994. The lines were developed using single seed descent (Brim, 1966). The recombinant inbred population was developed from the $\mathrm{F}_{2}$ through the $\mathrm{F}_{8}$ generation in the greenhouse by single seed descent, and the lines were planted in the field at Pullman for seed increase in 2000. The recombinant inbred lines (RILs) in the $\mathrm{F}_{8: 9}$ generation were evaluated in the RFDN in 2002, 2003, 2004, and 2005.

\section{Experimental Design and Field Evaluation} In 2002, 2003, and 2004, 93, 111, and 114 RILs, respectively, and three entries of each parent, were planted in the RFDN to screen for resistance to $F$. solani f. sp. pisi. Four lines of known resistant (PI 180693 [Grünwald et al., 2003], 90-2079 [Kraft 1992]) and susceptible ('Puget', 'Bolero') genotypes were added as controls. The highly susceptible cultivar Bolero was planted every 10th plot in 2002, 2003, 2004, and every 9th plot in 2005. In 2005 the eight most resistant lines and three entries of each parent were planted. A randomized complete block design was used each year, with three replications per entry. The lines were sown each April and evaluated for disease severity in June beginning with the completion of flowering until early pod-fill. Plots were sown with 30 seed in single $1.0-\mathrm{m}$ rows with 27.5-cm centers. Plots were hand weeded as necessary. Fertilization, pest control, and common cultural practices were consistent with pea production in eastern Washington. Plots were watered weekly with a single application of approximately $1.13 \mathrm{~cm}$ of water, which provided adequate moisture to maintain pea growth but created a relatively dry soil condition favoring Fusarium root rot development. Fusarium root rot is favored under dry soil conditions since root growth is reduced compared to an optimal watering regime where there are otherwise more competitive infections by Pythium spp. and A. euteiches pathogens, which are favored under continually wet or saturated soil. The soil at the RFDN consists of a Warden very fine sandy loam (coarse-silty, mixed, superactive, mesic Xeric Haplocambids) that has been cropped to peas for 19 of 22 yr from 1983 to 2005.

\section{Disease Resistance Evaluations}

Disease evaluation of the nursery in 2002 used an above-ground disease severity index at the flat pod stage evaluated on each whole plot using a 0 to 5 scoring scale developed by Pilet-Nayel et al. (2002). The severity index was as follows: $0=$ healthy plants; 1 = slight yellowing of lower leaves; 2 = graying, yellowing and necrosis of the lower leaves up to the third or fourth node, some stunting; 3 = graying yellowing and necrosis of half the plants in the plot, with a few dead plants; $4=$ stunting and necrosis of more than half of the plants, and more than half of the plants in a row are dead; $5=$ all plants dead.
Disease severity evaluations in 2003, 2004, and 2005 were based on a percentage scale (Hagedorn, 1960) assessing the amount of stunting, graying, yellowing and necrosis of the lower foliage scored from 0 to $100 \%$ ( 0 = healthy, $100=$ dead) in each plot.

\section{Statistical Analysis}

Data were analyzed using the SAS Version 9.1.2 (SAS Institute, 2003). Analysis of variance was conducted to determine differences among lines. Individual ANOVAs were calculated for each year. Years were considered homogeneous if the ratio of the effective error variances for disease resistance scores between years were less than 10-fold. The adjusted mean values of each line were used in the combined analysis and analyzed as a randomized complete block. Least square means and standard errors were used to determine if the lines were significantly different than the parents and controls. Multiple pairwise comparisons of means were conducted using Tukey's honestly significant difference (HSD) $(\alpha=0.05)$.

\section{Characteristics Agronomic Description}

Line W6 26740 (tested as RIL 846-34) is $45 \mathrm{~cm}$ in height, has normal leaf type, blooms at the 15 th node in $61 \mathrm{~d}$, produces two blunt pods per node, has seed with smooth green cotyledons with black hilum $(R, i, P l$, respectively). Seed weight

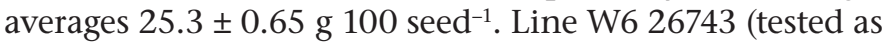
RIL 846-40) is $44 \mathrm{~cm}$ in height (le), has normal leaf type (Af), blooms at the 13th node in $57 \mathrm{~d}$, produces two blunt pods per node, and has seed with smooth green cotyledons with clear hilum $(R, i, p l$, respectively). Seed weight averages $19.8 \pm 0.49 \mathrm{~g} 100$ seed $^{-1}$. Line W6 26745 (tested as RIL $847-36)$ is $41 \mathrm{~cm}$ in height, has normal leaf type, blooms at the 13th node in $61 \mathrm{~d}$, produces two blunt pods per node, and has seed with wrinkled-green cotyledons with clear hilum $(r, i, p l$, respectively). Seed weight averages $16.4 \pm 0.12$ g 100 seed $^{-1}$. Compared with the resistant parent 90-2131, double pods are an improved agronomic trait that contributes to improved yield in the three release lines. Two lines, W6 26743 and W6 26745, have clear hilum required for food-type pea cultivars. All three releases are shorter vine types with acceptable seed size. The trait observations are summarized in Table 1.

\section{Disease Resistance}

Analysis of variance revealed highly significant variation between RILs within years $(P=0.0001)$. No significant difference for disease rating between years was detected. There was also no significant difference between replications within a year, and no significant year $\times$ genotype interaction was detected. The $R^{2}$ value indicated in the model explains $82.2,84.7,79.1$, and $86.1 \%$ of the variation for 2002, 2003, 2004, and 2005, respectively, and the coefficient variable $(14,36,57,27)$ is high for each year, but not unusual for field disease resistance data because of its extreme variability. The disease severity scores are presented in Table 2. The 2005 disease 
Table 1. Agronomic trait observation summary of seed and growth characteristics of green pea releases with resistance to Fusarium root rot.

\begin{tabular}{|c|c|c|c|c|c|c|c|c|c|}
\hline Name & Flower & Seed surface & Cotyledon & Seed coat & Hilum & Days $\mathrm{FF}^{\dagger}$ & Node FF & FPP§ & $\mathrm{HM}^{\Uparrow}$ \\
\hline & & & & & & $d$ & & & $\mathrm{~cm}$ \\
\hline DSP & white & wrinkled & green & clear & clear & 57 & 15 & 2 & 34 \\
\hline PI 180693 & pigmented & round & yellow & pigmented & black & 58 & 18 & 2 & - \\
\hline $90-2131$ & white & round & green & hyaline & black & 60 & 15 & 1 & 36.5 \\
\hline W6 26740 & white & smooth & green & clear & black & 61 & 15 & 2 & 45 \\
\hline W6 26743 & white & smooth & green & clear & clear & 57 & 13 & 2 & 44.5 \\
\hline W6 26745 & white & wrinkled & green & clear & clear & 61 & 13 & 2 & 41.5 \\
\hline
\end{tabular}

tDays FF, days to first flower in $50 \%$ of the plot.

¥Node FF, number of nodes to first flower.

${ }^{\S} \mathrm{FPP}$, number of flowers per peduncle.

"HM, plot height at pod maturity.

Table 2. Least square means of disease severity ratings of the parents, wild type, and recombinant inbred lines (RILs) of pea lines screened for Fusarium root rot resistance in the Roza Fusarium Disease Nursery in Prosser, WA, from 2002-2005.

\begin{tabular}{|c|c|c|c|c|}
\hline \multirow{2}{*}{ Entry } & \multicolumn{4}{|c|}{ Least square means } \\
\hline & 2002 & 2003 & 2004 & 2005 \\
\hline 'Dark Skin Perfection' (susceptible parent) & $4.67^{\dagger}$ & 86.67 & 73.33 & 97.08 \\
\hline PI 180693 (wild type) & $3.67(0.0284)^{\star}$ & $20.00(<0.0001)^{\ddagger}$ & $20.00(0.0016)^{\star \star}$ & $M D^{\S}$ \\
\hline 90-2131 (resistant parent) & $3.33(0.0051)^{\star \star}$ & $40.00(0.0002)^{\star \star \star}$ & $20.00(0.0016)^{\star \star}$ & $72.08(0.0549) \mathrm{NS}^{\Uparrow}$ \\
\hline W6 26740 (RIL 846-34) & MD & $18.33(<0.0001)^{\ddagger}$ & $6.67(0.0002)^{\star \star \star}$ & $35.41(<0.0001)^{\ddagger}$ \\
\hline W6 26743 (RIL 846-40) & $2.33(<0.0001)^{\ddagger}$ & $23.33(<0.0001)^{\ddagger}$ & $6.67(0.0002)^{\star \star \star}$ & $63.67(0.0132)^{\star}$ \\
\hline W6 26745 (RIL 847-36) & $2.83(0.0003)^{\star \star \star}$ & $26.67(<0.0001)^{\ddagger}$ & $13.33(0.0005)^{\star \star \star}$ & $33.75(<0.0001)^{\ddagger}$ \\
\hline SE & 0.29 & 7.51 & 10.73 & 9.69 \\
\hline
\end{tabular}

*Significant at the 0.05 probability level.

** Significant at the 0.01 probability level.

***Significant at the 0.001 probability level.

${ }^{\dagger} P$ values (in parentheses) represent the significance of the comparison between the line and the susceptible parent based on Tukey's honestly significant difference.

FSignificant at the 0.0001 probability level.

${ }^{\S}$ Missing data.

"NS, not significant.

evaluations were confounded by high levels of virus infestation in the nursery. Each release is significantly different from the susceptible parent using Tukey's HSD. There was a trend toward lower disease severity ratings of the release lines compared with the resistant parent using the standard error range; the disease ratings were lower for W6 26740 in all three field tests, and W6 26743 and W6 26745 were lower in three of four field tests (Table 2). Additionally, all three lines have improved agronomic characteristics with doubled pods; two lines have clear hilum required for food-grade pea.

\section{Availability}

Small quantities of seed are available from the corresponding author. Seed is also available from the Western Regional Plant Introduction Station (http://www.ars.usda. gov/pwa/pullman/wrpis). There are no restrictions on their use in breeding for pea cultivar improvement.

\section{Acknowledgments}

We thank Virginia A. Coffman for the planting and maintenance of the disease nurseries. These lines were developed with support from the USDA CSREES Cool Season Food Legume Special Grant Program to DAI, CJC, and KEM and ARS Project Nos. 5348-21000-017-00D (CJC), 5354-21220-015-00D (LDP), 5348-21000-014-00D (KEM).

\section{References}

Brim, C.A. 1966. A modified pedigree method of selection in soybean. Crop Sci. 6:220.

Hagedorn, D.J. 1960. Testing commercial pea varieties for reaction to Fusarium root rot, Fusarium solani f.sp. pisi. Phytopathology 50:637.

Haglund, W.A., and J.M. Kraft. 2001. Fusarium root rot. p. 14-16. In J.M. Kraft and F.L. Pfleger (ed.) Compendium of pea diseases and pests. 2nd ed. APS Press, St. Paul, MN.

Grünwald, N.J., V.A. Coffman, and J.M. Kraft. 2003. Sources of partial resistance to Fusarium root rot in the Pisum core collection. Plant Dis. 87:1197-1200.

Kraft, J.M. 1992. Registration of 90-2079, 90-2131, and 90-2322 pea germplasms. Crop Sci. 32:1076.

Pilet-Nayel, M.L., F.J. Muehlbauer, R.J. McGee, J.M. Kraft, A. Baranger, and C.J. Coyne. 2002. Quantitative trait loci for partial resistance to Aphanomyces root rot in pea. Theor. Appl. Genet. 106:28-39.

SAS Institute. 2003. SAS 9.1.2. SAS Inst., Cary, NC. 